\title{
Practice Innovation for Care Integration, Opioid Management, and Quality Measurement in Family Medicine
}

\author{
Anne Victoria Neale, PhD, MPH, Marjorie A. Bowman, MD, MPA, \\ and Dean A. Seebusen, MD, MPH
}

Ringing in the new year 2017! This may finally be the year of real practice improvement after many false starts. Research into practice transformation has informed both local work and national policy. Human factors and payment structures are key. And payment structures depend on how quality is measured. Large gaps between practicing physician recommendations for the most important quality measures and those currently imposed externally are exposed in this issue. Also see information on in-practice social work consultations and their outcomes and recommendations from innovators in integrated care, and for chronic opioid therapy management based on visits to many family medicine offices. Visit entropy is negative for hospital readmissions. Another article reaffirms the importance of family physicians in rural obstetrics, including Cesarean deliveries. Two articles address changing Latino health care access. New Mexico's innovative health extension agent implementation now includes research in ways that benefit all. And a glass half-full: the growth in the diversity of family medicine faculty is above average, but is not occurring as quickly as in the general population. (J Am Board Fam Med 2017;30:1-3.)

\section{The Transformation Challenge}

Restructuring primary care is essential to achieving the triple aim, and human factors are paramount to the success of clinic redesign. Zinc et $\mathrm{al}^{1}$ conducted a case-comparison study that revealed important human factor themes. Health system leaders underestimated the stress and role adjustment for clinicians and nursing personnel. Further, the patientcentered medical home model is not financially sustainable in a traditional fee-for-service environment.

New payment structures aim to pay based on quality. Yet, current quality measurements do not capture the essence of quality care, and burdensome reporting requirements reduce resources for patient care. The Core Quality Measures Collaborative, ${ }^{2}$ with input from the American Academy of Family Physicians, ${ }^{3}$ recently released a reduced core measures set for primary care, including condition-focused measures, preventive measures, and cross-cutting measures addressing medication rec-

Conflict of interest: The authors are editors of the $7 A B F M$. onciliation and items related to patient experience of care. Nowels and Kamerow ${ }^{4}$ argue that this new core quality measure set still fails to capture information about multidimensional health-related domains in patient's lives, including health outcomes of most interest to the patient. And a different group of investigators ${ }^{5}$ asked primary care physicians how they would measure quality of care. Read more on the enormous gaps between quality measurement recommendations from practicing physicians and those currently in existence or proposed for near-term implementation.

\section{Integrated Care}

Two articles inform the work to integrate care. Gold et $\mathrm{al}^{6}$ summarize 5 key recommendations from innovators who participated in the 3-year Advancing Care Together demonstration project on integrated care. And, in a retrospective records review of internal medicine outpatient practices, Rabovsky et $\mathrm{al}^{7}$ did not find significant changes in diabetes control after an in-office social work consultation. However, for the subgroup that had un- 
controlled diabetes or had diabetes with $\geq 1$ uncontrolled cardiovascular risk factor, social work consultations were associated with improvements in patient $\mathrm{HbA}_{1 \mathrm{c}}$ and low-density lipoprotein cholesterol levels. The social work consultations most frequently addressed obtaining medications or health insurance and social support. Over half of the patients in the practices had Medicare insurance, which could be important in determining who is most likely to benefit from social worker input.

The challenge of responding to prescription opioid overuse has everyone's attention. In an effort to identify common attributes of clinic system changes around managing chronic opioid therapy, Parchman et $\mathrm{al}^{8}$ conducted site visits at 20 primary care clinics nationwide, which were selected for their use of team-based workforce innovations. A common set of 6 best practices were identified that address complex challenges of managing chronic opioid therapy in primary care settings.

\section{Access to Care for Latinos}

Using data from the National Health Interview Survey, Alcalá et $\mathrm{al}^{9}$ examined access to, and utilization of, health care by Latino subgroups. These authors report that the Patient Protection and Affordable Care Act has reduced gaps for some. Remaining disparities may require new policy solutions for groups excluded from coverage. Work on dairy farms is year-round, rather than seasonal, so immigrant dairy workers are not eligible for federally funded health care at migrant health centers. ${ }^{10}$ In conjunction with a federally qualified health center, medical students offer free, on-site screening/ referrals for Spanish-speaking dairy farm workers. Lack of insurance and communication issues were the main barriers to health care, and these were addressed by helping workers navigate the federally qualified health center sliding fee scale and providing medical interpreting.

\section{Patient Care}

The chronic disease model suggests that continuity of care can reduce hospitalizations and improve outcomes for patients with multimorbidity. Continuity of care following hospital admission has had mixed effects on readmission rates; however, its effect before admission has not been well studied. Garrison et $\mathrm{al}^{11}$ studied a large cohort of primary care -patients from a patient centered medical home practice, exploring continuity of care in the 12 months before admission with 3 established metrics, plus a new measure of "visit entropy," to quantify the disorganization of visits. Higher visit entropy was associated with more readmissions among primary care patients, whereas other continuity measures were not.

Women's access to maternity care varies in rural areas and by state, with less than half of rural hospitals providing maternity care. Young ${ }^{12}$ reports that rural family physicians continue to provide the majority of maternity care in US rural hospitals, including cesarean deliveries.

Anderson and Strowd ${ }^{13}$ report various aspects of scabies in an outpatient dermatology clinic. A majority of diagnoses were made by physical examination (including dermoscopy), or by visualizing ova, feces, or mites on light microscopy. Informative pictures and dermatologist-recommended treatments are also provided.

\section{Innovation}

Applying aspects of the US Department of Agriculture's county-based agricultural Cooperative Extension Service, the community-based health extension regional officers model was developed and is well known for facilitating university-community engagement throughout New Mexico. Now, Kaufman et $\mathrm{al}^{14}$ describe how this bilateral engagement has been expanded to also involve research through interchange of the university's Clinical and Translational Science Center, the health extension regional officers, and their communities. Community engagement is at the heart of this creative approach to enhancing research.

\section{About the Family Medicine Profession}

The American Board of Family Medicine continues to conduct rigorous research to understand and improve its certification examination. O'Neill and Peabody ${ }^{15}$ examined the question of whether requiring diplomates to select only 1 content-specific module, rather than 2, would increase, decrease, or produce no change in scores for the examinee population. Results suggest that having examinees select only 1 testing module will likely produce a slight score increase and improve the standardization of the examination across examinees. 
Diverse medical school faculty attract diverse students, which is important for improving the health of minority and under-represented patients. Using data from the American Medical Colleges Faculty Roster, Xierali et $\mathrm{al}^{16}$ describes trends in the proportions of female and under-represented minority faculty. Family medicine has higher proportions of women and under-represented minority faculty than average, but lags behind population trends.

To see this article online, please go to: bttp://jabfm.org/content/ 30/1/1.full.

\section{References}

1. Zink T, Kralewski J, Dowd B. The transition of primary care group practices to next-generation models: satisfaction of staff, clinicians, and patients. J Am Board Fam Med 2017;30:16-24.

2. Centers for Medicare \& Medicaid Services. Core measures. Updated February 16, 2016. Available from https://www.cms.gov/Medicare/QualityInitiatives-Patient-Assessment-Instruments/ QualityMeasures/Core-Measures.html. Accessed October 31, 2016.

3. American Academy of Family Physicians. Quality measures: the Core Quality Measures Collaborative. Available from http://www.aafp.org/practice-management/ improvement/measures.html. Accessed October 31, 2016.

4. Nowels D, Kamerow DB. New "core quality measures": only a beginning. J Am Board Fam Med 2017;30:4-7.

5. Etz RS, Gonzalez MM, Brooks EM, Stange KC. Less and more are needed to assess primary care. J Am Board Fam Med 2017;30:13-15.
6. Gold SB, Green LA, Peek CJ. From our practices to yours: key messages for the journey to integrated behavioral health. J Am Board Fam Med 2017;30: 25-34.

7. Rabovsky AJ, Rothberg MB, Rose SL, Brateanu A, Kou L, Misra-Hebert AD. Content and outcomes of social work consultation for patients with diabetes in primary care. J Am Board Fam Med 2017;30:35-43.

8. Parchman ML, Von Korff M, Baldwin LM, et al. Primary care clinic re-design for prescription opioid management. J Am Board Fam Med 2017;30:44-51.

9. Alcalá HE, Chen J, Langellier BA, Roby DH, Ortega AN. Impact of the Affordable Care Act on health care access and utilization among Latinos. J Am Board Fam Med 2017;30:52-62.

10. Buckheit C, Pineros D, Olson A, Johnson D, Genereaux S. Improving health care for Spanish-speaking rural dairy farm workers. J Am Board Fam Med 2017;30:91-3.

11. Garrison GM, Keuseman R, Bania B, Robelia P, Pecina J. Visit entropy associated with hospital readmission rates. J Am Board Fam Med 2017;30:6370.

12. Young RA. Maternity care services by family physicians in rural hospitals. J Am Board Fam Med 2017; 30:71-7.

13. Anderson KL, Strowd LC. Epidemiology, diagnosis, and treatment of scabies in a dermatology office. J Am Board Fam Med 2017;30:78-84.

14. Kaufman A, Rhyne RL, Anastasoff J, et al. Health extension and clinical and translational science: an innovative strategy for community engagement. J Am Board Fam Med 2017;30:94-9.

15. O'Neill TR, Peabody MR. Impact of one versus two content-specific modules on American Board of Family Medicine certification examination scores. J Am Board Fam Med 2017;30:85-90.

16. Xierali IM, Nivet MA, Gaglioti AH, Liaw WR, Bazemore AW. Increasing family medicine faculty diversity still lags population trends. J Am Board Fam Med 2017;30:100-3. 